\title{
Livro de registro como estratégia no ensino de ecologia: bases históricas no Brasil
}

Record books as a strategy in ecology education: fundations historical in Brazil

\author{
Lucas Salvino Gontijo ${ }^{1}$ \\ Jenyffer Soares Estival Murça² \\ Jéssica Custódio da Silva Rabelo ${ }^{3}$ \\ Simone Sendin Moreira Guimarães ${ }^{4}$ \\ Andréa Inês Goldschmidt ${ }^{5}$
}

\section{Resumo}

O artigo apresenta uma revisão bibliográfica a respeito das bases históricas da Ecologia e uma atividade didática, demonstrando a importância do Brasil para o desenvolvimento da Ecologia, com base na História e Filosofia da Biologia. A atividade foi realizada com alunos do terceiro ano do ensino médio em uma escola pública de Goiânia, GO. Foram utilizadas três aulas de biologia para organizar a sequência em três momentos distintos: (1) aula expositiva-dialogada sobre as viagens naturalistas; (2) atividade prática sobre o que os naturalistas do século XIX faziam. Fornecemos a cada aluno um "diário de bordo" para fazer anotações sobre a atividade; e, (3) aula sobre os livros de registro de Eugen Warming, naturalista do século XIX, comparando-os com os trabalhos dos estudantes. A análise dos livros de registro dos alunos demonstrou que, apesar de não ter sido detalhado o método utilizado por Warming (textos, ilustrações e coletas), eles seguiram princípios semelhantes. Portanto, percebemos que esse tipo de abordagem é específica e pontual, sendo necessário evitar generalizações. Desta forma, a HFB auxilia o licenciando a compreender melhor a ciência que ensina, desde seus aspectos epistemológicos até as suas relações sociais e históricas.

Palavras chave: educação; formação docente; natureza da ciência; ecologia.

\section{Abstract}

The article brings a bibliographic review about the historical bases of Ecology with a didactic activity, demonstrating the importance of Brazil for the development of Ecology, based on the History and Philosophy of Biology. The activity was accomplished with students of the

\footnotetext{
${ }^{1}$ Universidade Federal de Goiás | lucas.sgo@outlook.com

${ }^{2}$ Pontifícia Universidade Católica de Goiás | jenyfferstival@gmail.com

${ }^{3}$ Universidade Federal de Goiás | jessica.bio.ufg@gmail.com

${ }^{4}$ Universidade Federal de Goiás | sisendin@gmail.com

${ }^{5}$ Universidade Federal de Santa Maria | andreainesgold@gmail.com
} 
last year of high school in a public school in Goiânia, Goiás. We used three biology classes to organize the activity in three different moments: (1) classes-dialogue about naturalist journeys; (2) practical activity about what nineteenth-century naturalists did. We provided to each student a "log book" to make notes about the activity; and (3) class about the "log books" of Eugen Warming, nineteenth-century naturalist, comparing with the students works. The analysis of student's log books showed that, although Warming's method (texts, illustrations and collections) had not been detailed, they followed similar principles. Therefore, we realized this type of approach is specific and exact, avoiding generalizations. The HFB can help the future teacher to understand better the science that teaches, from epistemological aspects to the social and historical relations.

Keywords: education; teacher training; nature of science; ecology.

\section{Introdução}

São vários os problemas relacionados à educação, desde os que envolvem políticas públicas até a relação professor-aluno nas unidades escolares. Devido à complexidade do atual quadro, faz-se necessário a discussão de questões mais pontuais, como o processo de formação docente e a forma como o conhecimento científico é ensinado aos estudantes da Educação Básica (EB). O modelo de cursos de formação de professores de ciências/biologia, frequentemente, não tem destinado espaços que possibilitem discussões acerca da construção e produção do conhecimento científico segundo a Natureza da Ciência (BRANDO et. al, 2012). Entender a ciência como objeto em construção num processo contínuo, torna o profissional docente muito mais preparado para mediar o conhecimento do aluno, baseado inicialmente nas experiências pessoais, para outro, mais elaborado em termos de conhecimento científico.

Matthews (1995) destaca a presença de índices elevadíssimos de analfabetismo científico tanto nas instituições de formação de professores quanto na educação básica, evidenciando a relação que a formação de professores e a educação básica estabelecem com o ensino de ciências. Como possibilidades para enfrentamento da questão são apontadas possíveis contribuições que a História e Filosofia da Biologia (HFB) podem oferecer. Para Brando et al (2012) discussões históricas contribuem para superar o ensino fragmentado, possibilitando uma abordagem interdisciplinar. Além disso, pode possibilitar com um ensino mais contextualizado e crítico.

Melzer e Aires (2015) discutem que o desejável é que a abordagem HFC possibilite a compreensão de como os fatos narrados foram produzidos, quais indivíduos estiveram envolvidos nessa produção e como esses fatos estão interligados com os aspectos sociais, políticos e econômicos de determinada época.

No que diz respeito à importância da inserção da HFB nos cursos de formação, compreendemos que o conhecimento histórico específico acerca das subáreas (Ecologia, Genética, Botânica, etc) da Biologia, além de favorecer a compreensão da construção de cada um desses campos do conhecimento, possibilita integrar as diversas áreas de estudo que a compõe enquanto ciência, capacitando-nos a "questionar concepções e práticas assumidas de forma acrítica e a aproximação de concepções epistemológicas mais 
adequadas que, se devidamente reforçadas, podem ter incidência positiva sobre o ensino" (GIL-PÉREZ et al, 2001, p. 127).

O presente artigo teve por objetivo realizar uma revisão bibliográfica a respeito das bases históricas da Ecologia, bem como sua consolidação como ciência, buscando evidenciar a importância do Brasil neste processo. Além disso, propomos a elaboração e desenvolvimento de uma atividade prática na subárea Ecologia sob a perspectiva da História e Filosofia da Biologia no ensino de Biologia na Educação Básica.

\section{História da Ecologia}

As relações entre os seres vivos e o meio onde vivem sempre levantaram questionamentos ao longo da história. O advento das Ciências Naturais entre os séculos XVI e XIX, principalmente no campo da botânica e zoologia, contribuiu para o desenvolvimento de uma ciência que mais tarde se consolidou como Ecologia. Muitas vezes nos cursos de formação de professores a abordagem histórica acerca de uma área específica resigna-se em relatos gerais que desconsideram um estudo mais profundo e, portanto, mais rico. Tratar o Brasil como locus importante, a partir do qual foram lançadas as bases para diversos estudos científicos é, em vários casos, uma atitude negligenciada tanto em cursos de formação docente como no ensino básico.

Por este motivo, este artigo lança mão de um episódio ocorrido no Brasil do século XIX a fim de demonstrar a relevância de fatos específicos e sua relação com o advento de áreas importantes do saber. A Grande Missão Austríaca de 1817 abriu caminho para uma miríade de naturalistas europeus daquele período, oportunizando a chance de alavancar seus estudos e pesquisas. Antes de abordar a respeito da expedição propriamente dita é necessário conhecer um pouco dos dois cientistas que lideraram tal incursão.

Johann Ritter Baptist von Spix (1781-1826) nasceu na cidade alemã Hochstadt der Aisch. Por ser de família pobre ingressou aos 11 anos na Escola Episcopal de Bamberg e aos 12 foi transferido para o Seminário Episcopal da mesma cidade. Aos 19 anos doutorou-se em Filosofia e aos 23 começou a estudar Medicina e Ciências Naturais. Por dois anos o rei Maximiliano José I custeou os estudos de Spix em Paris, centro de estudos em zoologia da época, onde conviveu com grandes nomes da ciência como Georges Cuvier (1769-1832), Jean-Baptiste de Lamarck (1744-1829) e Auguste de Saint-Hilaire (1779-1853). Em 1807, com 26 anos, já era doutor em medicina. No ano seguinte o rei Maximiliano contratou Spix para organizar a Academia Real de Ciências em Munique. Mais tarde ficou responsável por desenvolver pesquisas importantes sobre anatomia morfológica e biologia evolutiva. Seu vasto conhecimento em história natural aliado às viagens científicas que realizou, renderamIhe renome no meio científico (FITTKAU, 2001).

Ao contrário de Spix, Carl Friedrich Philipp von Martius (1794-1868) era de família nobre. Nasceu na cidade de Erlangen, região da Baviera, Alemanha. Seu pai era professor honorário na Universidade de Erlangen, o farmacêutico Ernst Wilhelm Martius. E sua mãe, Regina, era da nobre e influente família Weinl. Desde pequeno foi influenciado pelo pai em questões científicas, demonstrando nítido interesse pela botânica. Ainda na educação básica em Erlangen se empenhou profundamente nos estudos de textos das Culturas da Antiguidade Clássica, tendo aprendido e praticado grego e latim, além de exercitar o gosto por História Natural. Em 1810, então com 16 anos, iniciou seus estudos em Medicina na 
mesma universidade em que o pai atuou. Lá estudou com o professor Johann C. D. von Schreber (1739-1810), importante botânico da época que foi aluno de Carolus Linnaeus (1707-1778) (CHIQUIERI, 2001).

Após a breve biografia de Spix e Martius, enfim, a Missão Austríaca será abordada em seus aspectos gerais, de modo a esclarecer a participação do Brasil neste episódio tão importante para a História da Ciência Natural e como o país desenvolveu raízes profundas em diversas áreas do conhecimento.

Desde a chegada dos portugueses ao Brasil, em 1500, até o período de tensão política que se estabeleceu em Portugal, em meados do século XVIII, o trabalho científico nessa parte das Américas foi muito limitado principalmente pelas restrições em relação aos portos da colônia. Contudo, era do conhecimento da comunidade científica europeia deste período o imenso potencial que "o novo mundo" oferecia no campo do trabalho científico, principalmente o Brasil. Sua grande extensão territorial, população demográfica baixa e condições ambientais favoráveis, faziam da colônia um imenso campo de pesquisa que não fugia aos olhos da elite ligada ao saber (MONTEIRO, 2011). Por este motivo sua majestade, o Rei da Baviera Maximiliano José I, movido pelo desejo de aproximar a humanidade de um conhecimento mais íntimo da América, requisitou, no ano de 1815, à Academia Real de Ciências de Munique uma ordem para que fosse organizada uma viagem científica ao interior da América do Sul. Para providenciar a viagem o rei escolheu Spix, que ficou a cargo da zoologia, e Martius para botânica. O plano era partir de Buenos Aires por terra até ao Chile, depois seguiriam para o norte até Quito. Finalmente, passando por Caracas ou México regressariam à Europa (LISBOA, 1995).

Infelizmente, por motivos diversos o objetivo do rei precisou ser adiado. No entanto, surgiu, em 1817, a oportunidade que o monarca tanto almejava, e sem demora acionou novamente a Academia Real de Ciências e os cientistas antes escolhidos para a missão. Foi firmada naquele ano uma aliança entre Portugal e Áustria, e para oficializar tal união seria realizado no Brasil o casamento entre Sua Alteza D. Carolina Josefa Leopoldina de Habsburgo-Lorena, Arquiduquesa da Áustria, com Sua Alteza Real D. Pedro de Alcântara, Príncipe herdeiro de Portugal, Brasil e Algarves. Mais tarde D. Pedro I e Maria Leopoldina, rei e rainha. O rei da Baviera presente em Viena, desejoso de seu intento, resolveu junto à corte imperial, fazer seguir no séquito da noiva cientistas austríacos, membros da Academia (BRAGA, 2006).

No dia 28 de janeiro de 1817 o rei Maximiliano da Baviera emitiu o aviso para que Martius e Spix seguissem com urgência para Viena, e depois Trieste, onde embarcariam nas fragatas que já estavam prestes a partir para o Rio de Janeiro. Ao mesmo tempo a Academia Real de Ciências recebeu ordens para encarregar Spix e Martius de problemas científicos, tanto nas áreas principais, zoologia e botânica, como em tudo aquilo que estivesse ao alcance das observações e pesquisas. A Academia tratou de fornecer o que fosse necessário e cujo uso traria resultados para a ciência. (LISBOA, 1995).

A Missão Austríaca de 1817-1820, ao contrário do que muitos julgam, não tinha como único objetivo pesquisar botânica e zoologia. Os resultados obtidos com tal empreitada foram muito mais além, contribuindo com outras áreas do conhecimento como política, sociologia, antropologia, geologia, medicina, línguas, estudos culturais e étnicos, e, dentre outras ciências, a ecologia. $O$ trabalho pioneiro de Martius e Spix, além de servir como base substancial para o contínuo desenvolvimento das Ciências Naturais, foi também motivação para que outros cientistas se empenhassem em realizar pesquisas neste novo e promissor 
campo de estudos. Após o retorno dos expedicionários para a Europa, outros aportaram em terras brasileiras e se tornaram figuras importantes para a Ciência. Dentre esses personagens memoráveis trataremos agora daquele que fez do Brasil a peça fundamental para a consolidação da Ecologia como ciência independente: Johannes Eugenius Bulow Warming (1841-1924).

Não é possível falar sobre Warming e a importância que o Brasil teve para seu trabalho sem antes conhecer aquele que foi o elo entre este cientista tão relevante e a Pátria Amada. Por este motivo reservamos aqui espaço para uma breve narrativa sobre o dinamarquês Peter Wilhelm Lund (1801-1880). Para enfatizar ainda mais as relações que existiram entre cientistas europeus e o Brasil, retiramos o recorte a seguir da página eletrônica da prefeitura de Lagoa Santa, MG. Cidade que considera Lund um cidadão/filho até hoje.

Peter Lund nasceu em 14 de junho em Copenhagen, Dinamarca. Filho de comerciantes ricos, o jovem ingressou na Universidade de Copenhagen e logo demonstrou interesse pelas Ciências Naturais. Era uma pessoa muito doente e sofria de sérios problemas pulmonares. Ao contrair tuberculose, os médicos recomendaram que Lund se mudasse para uma região de clima mais benéfico para seu estado. Viu então no Brasil a oportunidade para cuidar de sua saúde e, além disso, aprofundar seus estudos em zoologia e botânica. Estabeleceu-se no Rio de Janeiro no ano de 1825 e durante 4 anos realizou exaustivos levantamentos de toda vegetação da baixada fluminense, além de observar o comportamento de formigas, montando posteriormente algumas coleções zoológicas. Em 1829 retornou à Europa, e lá se associou ás maiores autoridades em História Natural da época como Humbold e Cuvier (LAGOA SANTA, 2015).

Em 1833 mudou-se definitivamente para o Brasil, já iniciando uma expedição ao lado do botânico L. Riedel (1790-1861) a fim de estudar a flora brasileira. Foi nesta mesma viagem que Lund encontrou seu contemporâneo, o dinamarquês Peter Claussen (1804-1855), na região de Curvelo, Minas Gerais, na ocasião Claussen explorava salitre nas cavernas calcárias. Ao visitar as cavernas da região, Lund encontrou e reconheceu, pela primeira vez na história do Brasil, ossadas misturadas ao salitre. Diante desta e outras descobertas, ele decidiu por uma nova área de pesquisa, a paleontologia. Logo depois de concluir os estudos intitulados "A respeito da Vegetação dos Campos do Brasil", fixou residência em Lagoa Santa, considerado por ele lugar ideal para viver. Em tais grutas Lund encontrou várias ossadas já fossilizadas, com especial destaque para o Smilodon populator (tigredente-de-sabre), o Glyptodon clavipes (Tatu Gigante) e o Nortrotherium maguinense (preguiça gigante). Foram pesquisadas mais de uma centena de grutas das quais resultaram nas descobertas de 120 espécies fósseis extintas e 94 fósseis da fauna atual. Em 10 anos de trabalho reuniu 14 mil peças ósseas, que foram enviadas à Dinamarca, e posteriormente estudadas por Herluf Reinhard. Por conta de seu importante trabalho, Lund é ainda hoje considerado pai da paleontologia brasileira. Contudo, em 1844 perdeu vigor físico, e, assim, abandonou as pesquisas de campo interrompendo seu trabalho científico, passando a viver em completo isolamento (LAGOA SANTA, 2015).

Filho de pastor religioso, Warming ingressou na universidade de Copenhagen no mesmo ano em que Charles Darwin (1809-1882) publicou seu livro "A Origem das Espécies". Impulsionado pelo desenvolvimento da História Natural, fez da botânica sua área de interesse e pesquisa. Em 1862 o professor de zoologia da Universidade de Copenhagen, J.T. Reinhardt (1816-1882), que acompanhava os trabalhos de Warming de perto, convidou-o a vir ao Brasil para trabalhar com o renomado zoólogo dinamarquês Peter Lund, na função 
de assistente. Warming partiu de navio no dia 17 de fevereiro de 1863 e sete semanas depois aportou no Rio de Janeiro. Permaneceria no Brasil por três anos para, posteriormente, continuar seus estudos na Europa. Assim que colocou os pés em terras brasileiras se encantou com o lugar, reconhecendo ser uma cidade capaz de lhe oferecer todas as comodidades necessárias, além da natureza tropical tão diferente da vegetação predominante em sua terra. Alguns meses depois Warming seguiu viagem para Minas Gerais e, ao cabo de 42 dias, chegou na região de Lagoa Santa (FLORI, 2013).

O cientista não deixou de anotar as belezas do caminho em seu diário particular, fazendo referências às "flores azuis, em forma de sino, e muitas outras que ornavam as colinas dos campos e o orvalho como pérolas no meio das ervas" (KLEIN, 2002, p. 10). No dia 8 de julho daquele ano, Eugenius Warming chegou em Lagoa Santa e, enquanto passava pela praça da cidade, contemplou a casa de Lund. No mesmo diário, o cientista expressou sua excitação e alegria por estar prestes a conhecer homem tão importante e renomado para a ciência. Quem o recebeu foi um colaborador que ocupava interinamente o cargo de assistente. Warming, então com 22 anos, descreve seu mentor como "um senhor magro e grisalho que deu boas-vindas em alemão, mas que logo percebeu que poderia falar dinamarquês" (KLEIN, 2002, p. 10). Registrou também que Lund era um homem finíssimo e de boa educação, muito bem relacionado com os mais notáveis cientistas da Europa e que, mesmo frequentando altas rodas científicas e diplomáticas, escolheu aquela cidade para estabelecer sua residência.

Eugenius Warming permaneceu três anos no Brasil. Mesmo cumprindo as funções de assistente de Peter Lund, o cientista passou a desenvolver trabalhos independentes, que resultaram na publicação de um livro sobre a vegetação de Lagoa Santa. Seu modo de pesquisa perseguia uma botânica interpretativa, que considerava características climáticas e edáficas, que tentavam explicar a forma que os vegetais apresentavam relacionando-a com a frequência das queimadas decorrentes do clima da região. Warming é até hoje considerado o "pai" da ecologia e durante os três anos que viveu no Brasil estudou a vegetação do cerrado. De seus trabalhos na região de Minas Gerais obteve como resultado - livro Lagoa Santa: et bridrag til den biologiske plantegeografi (Lagoa Santa: contribuição para a geografia fitobiológica) publicado em 1892. Mais tarde, foi reconhecido mundialmente como principal precursor desta nova ciência chamada Ecologia com a publicação do livro Plantesamfund Grundtraek af den okologiske Planteogeografi (1895), jamais traduzido para o português (POLINARSKI et al., 2010)

Apesar de vários trabalhos em Ecologia terem sido publicados a partir de 1890, Eugenius Warming ocupa lugar de importância por ser o pioneiro em publicações específicas para esta área da ciência. Suas ideias e pensamentos sobre geobotânica ecológica serviram de motivação até para os zoólogos adotarem métodos utilizados na pesquisa científica desde os séculos passados, um de grande importância é o uso de diários de anotações.

Para qualquer pesquisador que atue no campo é de fundamental importância conhecer bem seu objeto de estudo. Os diários de anotações, muitas vezes chamados de "cadernetas de campo" pelos pesquisadores de hoje, existem justamente para guardar aquelas informações relevantes que não podem ser coletadas e levadas ao laboratório. Por este motivo, botânicos, zoólogos, geógrafos, geólogos e ecólogos, por exemplo, ainda não abandonaram o uso desse recurso antigo, porém muito útil. Neste sentido, Paz et al. (2014) defendem que utilizar esse instrumento pode auxiliar alunos em aulas práticas a 
compreender a importância da preservação e a relevância de cada elemento presente no local da aula de campo. É nessa perspectiva que se situa a atividade pedagógica relatada a seguir.

\section{Trajetória metodológica}

A partir da fundamentação histórica indicada anteriormente, a atividade didática foi desenvolvida em duas turmas de terceiro ano do Ensino Médio (noturno) de uma escola pública do estado de Goiás. O trabalho foi desenvolvido por três bolsistas PIBID da área de ciências biológicas em parceria com o professor supervisor e responsável pela turma.

A atividade, pensada a partir do referencial histórico levantado, foi organizada em uma sequência didática desenvolvida imediatamente antes do professor de biologia iniciar o conteúdo de Ecologia previsto no calendário escolar. Foram utilizadas três aulas (45 minutos cada) de biologia em cada turma. As aulas não eram no mesmo dia o que possibilitou organizar três momentos distintos.

A primeira aula foi teórica (expositiva-dialogada) e objetivou apresentar a expedição austríaca ocorrida entre 1817 e 1820, ressaltando a importância do Brasil no cenário científico da época como campo de estudo, principalmente da História Natural. Estabelecemos uma ordem cronológica para melhor entendimento dos alunos, relatando de maneira geral como se deu tal expedição, destacando pontos essenciais segundo nosso objetivo.

Destacamos que até então, no século XIX o naturalista assumia papel do biólogo e ao invés das subdivisões da biologia, as áreas do conhecimento mais difundidas eram a botânica e a zoologia. Tanto Spix quanto Martius, zoólogo e botânico respectivamente, não ficaram restritos à apenas suas áreas de domínio, sendo responsáveis também por coletar dados que iam desde mineralogia até o costume dos habitantes locais, passando pela política e características de povos indígenas. Procuramos deixar claro que o método utilizado pelos naturalistas para registrar as informações consistia em anotações feitas em diários, bem como descrições minuciosas e desenhos precisos do que era observado e que, mais tarde, esses registros constituíam a base para a elaboração de trabalhos científicos. Nesta aula também foi apresentada a história do botânico dinamarquês Eugenius Warming e seu trabalho com as plantas do cerrado mineiro, destacando a importância desse bioma. Na história de Eugen Warming também demos especial atenção para seus registros, que, assim como faziam os naturalistas do século XIX, também eram compostos por anotações em livros e diários, acompanhados por descrições, ilustrações e esquemas.

A segunda aula foi reservada para uma atividade prática desenvolvida no pátio da escola. Foi explicado que o objetivo desta atividade era fazer algo semelhante ao que os naturalistas do século XIX faziam: observar determinada área e registrar, por meio de descrição, ilustração ou esquema, o maior número de características possíveis. Para cada aluno foi fornecido um "livro de registro". Os livros foram preparados previamente e consistiam em cinco folhas de papel A4 dobradas ao meio e posteriormente encadernados. Por ser no período noturno, pedimos para que os alunos trouxessem lanternas para a realização da atividade. No início da aula deixamos a sala e conduzimos os estudantes para o pátio da escola. Após cada um escolher uma área de aproximadamente um metro quadrado $\left(1 \mathrm{~m}^{2}\right)$ iniciou-se o período de observações. Durante os quarenta e cinco minutos de aula os estudantes registraram dados como: o tipo de vegetação; presença de insetos ou outros organismos; altura dos vegetais; presença de alvenaria; tipo, cor e textura do solo, 
etc. Ao decorrer deste tempo fomos chamados para tirar dúvidas a respeito do que foi visto na aula teórica e para dar sugestões sobre o que registrar. Optamos por não dar muitos detalhes a respeito de como são os registros dos naturalistas para que os alunos pudessem exercitar sua criatividade. Ao término da aula retornamos para a sala e recolhemos o material produzido pelos estudantes.

A terceira e última aula foi utilizada como feedback. Fizemos uma breve revisão sobre o que foi dito na primeira aula, com especial atenção para os livros de registros dos naturalistas. Então, com o auxílio de projetor de imagens, mostramos retratos de Spix, Martius e Warming. Abrimos espaço para a participação dos estudantes partindo da seguinte pergunta: $O$ que você acha que aprendeu com a atividade desenvolvida no pátio da escola? Após alguns minutos apresentamos fragmentos de cartas de Eugen Warming, bem como ilustrações e fotografias de coletas realizadas pelo próprio cientista. Explicamos que este material está disponível em museus de ciências naturais na Europa, e pode ser acessado via internet, destacando sua importância para a construção da Ciência. Em seguida perguntamos se algum aluno foi capaz de fazer registros semelhantes aos que o botânico fez. A fim de incitar mais debate, mostramos fotografias de diários elaborados pelos próprios estudantes, preservando a identidade dos mesmos. Ao término da aula devolvemos os trabalhamos devidamente avaliados segundo os critérios de comparação (entre fragmentos de Eugen Warming e os livros desenvolvidos pelos alunos) que levaram em consideração o tipo de registro, ilustração ou escrita; o que foi observado, com especial atenção aos detalhes; e o "estilo" de registro, se descrições mais técnicas ou mais informais.

\section{Resultados e discussão}

No atual modelo de formação de professores é comum encontrar futuros profissionais que não experimentam a prática em sala de aula. O período de contato com escolas durante o curso de graduação é pequeno e geralmente só acontece no final do curso via estágios curriculares supervisionados. Uma das formas de ampliar esses momentos de inserção na escola de maneira crítica e reflexiva pode ser via PIBID, que entre outras coisas pode fomentar projetos que promovam situações em que o futuro professor pense em alternativas didático-pedagógicas. Este trabalho parte da necessidade de reflexão a respeito da prática docente, bem como da carência de alternativas didáticas e ferramentas que buscam melhor eficácia no processo de ensino-aprendizagem.

Campos e Nigro (2009) afirmam que tendo o professor, objetivos claros a serem alcançados com determinado conteúdo, e estando seguro de si e de seu papel quanto educador, o mesmo será capaz de realmente propiciar aprendizagem, possibilitar o desenvolvimento e utilizar o melhor caminho metodológico. Assim, poderá também escolher de forma coerente a modalidade didática a ser utilizada, como também os instrumentos explorados em aula. Os autores classificam algumas modalidades didáticas como Demonstrações práticas; Experimentos ilustrativos e descritivos; e Instrumentos didáticos.

Baseado nos mesmos autores, nossa proposta didática pode ser classificada como experimentos ilustrativos e descritivos, por ter como objetivo ilustrar e apresentar técnicas, fenômenos, espécimes, etc., possibilitando ao aluno relacionar a realidade com uma teoria abstrata (buscando desenvolver a autonomia), promover uma aprendizagem significativa e transformar a visão da ciência como uma interpretação do mundo e não como respostas 
prontas. Desse modo, investigações, ou experimentos investigativos que promovem o debate de ideias, se configuram como possibilidades para o estudante vivenciar um ciclo investigativo, respeitando seus limites de desenvolvimento cognitivo.

Souza (2014) acredita que experimentos, aulas práticas ou mesmo excursões não carecem de locais sofisticados para serem realizados. Conta-se com a criatividade do professor em utilizar o que é disponibilizado, tanto espaços físicos como instrumentos, para desenvolver esses tipos de modalidades na própria sala de aula, no pátio da escola ou em áreas próximas.

Do ponto de vista metodológico, o registro dos naturalistas consistia em, segundo Andrade e Bastiani (2012), modalidades textuais diversas como entrevista e relato oral, testemunhos, crônicas e memórias, motivados pela cosmovisão Europeia retratando uma realidade impressionista. Nesses registros podem ser encontradas descrições morfológicas precisas de espécies de plantas e animais; das singularidades de cada região, como pluviometria e temperatura; as características geológicas e mineralógicas do solo; narrativas a respeito da cultura local, dos costumes e dos hábitos da população; discussões acerca da política e economia vigente; além de registros visuais em imagens perfeitas e fidedignas da paisagem, fisionomia dos biomas e desenhos científicos de plantas, animais e rochas (LISBOA, 1995).

Discutir, mesmo que brevemente, essa questão histórica e metodológica possibilita conhecer as bases que fundamentam a construção da Ciência enquanto conhecimento continuamente adquirido (MATTHEWS, 1995). Diante disso, aliar a História e Filosofia da Ciência ao ensino de Ecologia através de atividades práticas, se configura em uma maneira de contribuir para a melhor formação do estudante na Educação Básica.

Borges (1997) defende que em qualquer sala de aula é possível desenvolver aulas práticas sem demandar instrumentos onerosos. Afirma também que com essas atividades, os estudantes se tornam capazes de obter, por meio de novas experiências, um conhecimento mais profundo acerca dos fenômenos naturais. Assim, entendemos que a elaboração dos livros de registros realizada pelos alunos de ensino médio como atividade prática do conteúdo de Ecologia, oportunizou a realização de um comparativo acerca do modo de pensar cientificamente dos estudantes retratando a maneira como Eugen Warming coletava/registrava seus dados de pesquisa.

A primeira aula, em caráter expositivo-dialogado, não diferiu do tradicional. A maioria dos alunos se manteve atentos às explicações tendo suas dúvidas sanadas na medida em que surgiam. Contudo, percebemos maior interesse e curiosidade pelo assunto. Ao término do desenvolvimento de toda a atividade, questionamos os motivos que levaram ao maior interesse e, como resposta, alguns estudantes relataram que não estão acostumados a este tipo de abordagem, que trata de um contexto histórico mais específico relacionado ao conteúdo trabalhado naquele momento do bimestre. Segue um breve relato, registrado em áudio com autorização dos alunos e do professor:

Aluno A:

"A gente não está acostumado com isso, com estudar história em biologia. E é legal porque a gente vê né? Como foi que os homens fizeram naquela época pra chegar hoje em dia...".

Diante de outros relatos como este percebemos o quão positiva pode ser a inserção da História e Filosofia da Ciência no ensino básico. Concordamos com Matthews (1995) ao 
defender um ensino mais significativo e contextualizado, pois dessa forma tal ensino, ao menos, fará sentido. Essa inserção queria superar a perspectiva de uma aula de definições e conceitos prontos, na qual o aluno aprende biologia por que caia na prova ou no ENEM. Para fugir dessa realidade tão comum, Alarcão (2001) defende que a escola que objetivamos na condição de professores é aquela reflexiva, tida como instituição que pensa em si própria continuamente, em seu papel social e em sua organização, confrontando-se com o proceder de sua atividade simultaneamente formativa e avaliativa. Acreditamos que formar é criar contextos de aprendizagem, um ambiente favorável ao cultivo de atitudes saudáveis e que promova as capacidades de cada indivíduo visando ao desenvolvimento das competências que lhes permitam viver em sociedade.

Alunos formados por uma escola com esses moldes estarão mais aptos para superação de obstáculos e para viver criticamente sua realidade. Estarão habituados a refletir, tendo motivação para continuar buscando a aprendizagem e o senso investigativo. E reconhecendo as dimensões afetivas e cognitivas poderão reagir melhor frente às mudanças e riscos que determinam uma sociedade em profunda transformação.

A parte prática da atividade, ocorrida na segunda aula, foi mais interessante no sentido de participação dos alunos. Apesar de ter ocorrido no período noturno, os estudantes utilizaram lanternas e smartphones para iluminar as áreas do pátio, escolhidas para a observação. Já de início vários deles chamaram atenção para o fato de que os naturalistas dos séculos passados não contavam com tais recursos em suas expedições, o que, na opinião da turma, era um fator limitante para as pesquisas. A princípio tiveram dificuldade para entender o significado de "observar e descrever". Com isso, pudemos perceber que muitos possuem seu "olhar científico" pouco, ou nada, desenvolvido diante de perguntas como: "o que eu devo observar?" ou "como devo descrever?".

Para que não ficassem completamente desorientados na atividade, fazendo esta perder o sentido, demos orientações básicas. Em alguns casos foi necessário mostrar, por exemplo, que existiam diferentes espécies de plantas ou que em um pequeno espaço havia insetos e vegetais coexistindo num mesmo ambiente. A partir de então a maioria entendeu a proposta e começaram a trabalhar com os livros de registro. Em posse do material devidamente recolhido após a aula, pudemos analisar cuidadosamente os livros elaborados pelos alunos e comparar com os diários e registros de Eugen Warming. Tais registros seculares estão disponíveis em arquivos digitais gratuitos na internet e são constituídos por textos (principalmente cartas e anotações sucintas), desenhos (ilustrações elaboradas e detalhadas, bem como esquemas quase indecifráveis) e coletas de material. No caso de Warming, o objeto de estudo coletado resumia-se a exemplares vegetais.

Realizar essa comparação nos fez perceber que, apesar de não ter sido detalhado o método utilizado por Warming (textos, ilustrações e coletas), os estudantes seguiram princípios semelhantes. Muitos elaboraram descrições detalhadas da morfologia vegetal utilizando uma linguagem poetizada, tal como o cientista fazia em suas anotações, como por exemplo:

Após ter passado a noite na fazenda de Manoel, partimos de manhã, ele e eu, a cavalo, pelo caminho que levava a Lagoa Santa. A manhã estava agradável. Flores azuis, em forma de sino, e muitas outras ornamentavam as colinas dos campos e o orvalho era como pérolas no meio das ervas. Por volta das dez horas, chegamos a Lagoa Santa e deixei meu olhar passear sobre a grande praça no meio da cidade e lá Manoel me mostrou 
a casa de Lund. A viagem, desde o Rio de Janeiro, havia durado 42 dias.

Chegava, finalmente, ao fim (KLEIN, 2002, p. 10).

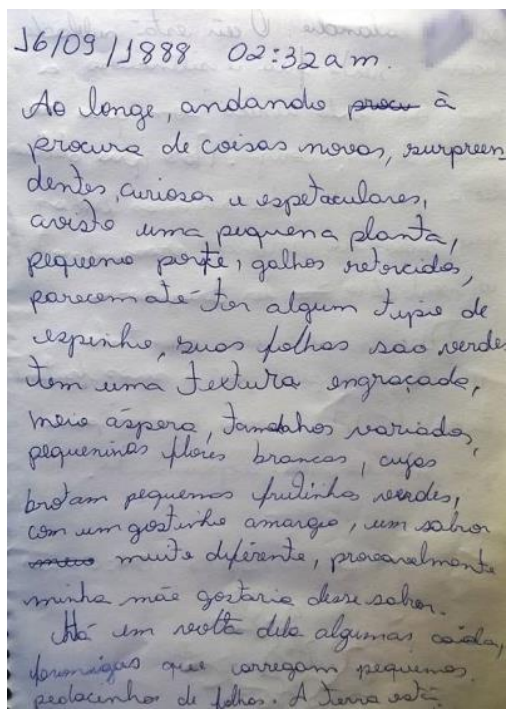

\section{6/09/1988 02:32am}

Ao longe, andando à procura de coisas novas, surpreendentes, curiosas e espetaculares, avisto uma pequena planta, pequeno porte, galhos retorcidos, parecem até ter algum tipo de espinho, suas folhas são verdes, tem uma textura engraçada, meio áspera, tamanhos variados, pequeninas flores brancas, cujas brota, pequenas frutinhas verdes, com um gostinho amargo, um sabor muito diferente, provavelmente minha mãe gostaria desse sabor. Há em volta dela algumas formigas que carregam pequenos pedacinhos de folhas. A terra está bem fofa e fértil.

Figura 1: Fragmento retirado de um livro de registro elaborado por um estudante Fonte: acervo pessoal dos autores; e, transcrição, respectivamente.

Não apenas descrições, mas também ilustrações e coletas foram realizadas pelos alunos. E quando comparadas aos registros dos cientistas, essas representações demonstram claramente o caminho metodológico adotado pelos mesmos. A seguir apresentamos imagens que contrapõem o que foi elaborado por Eugen Warming e o que foi feito pelos estudantes.

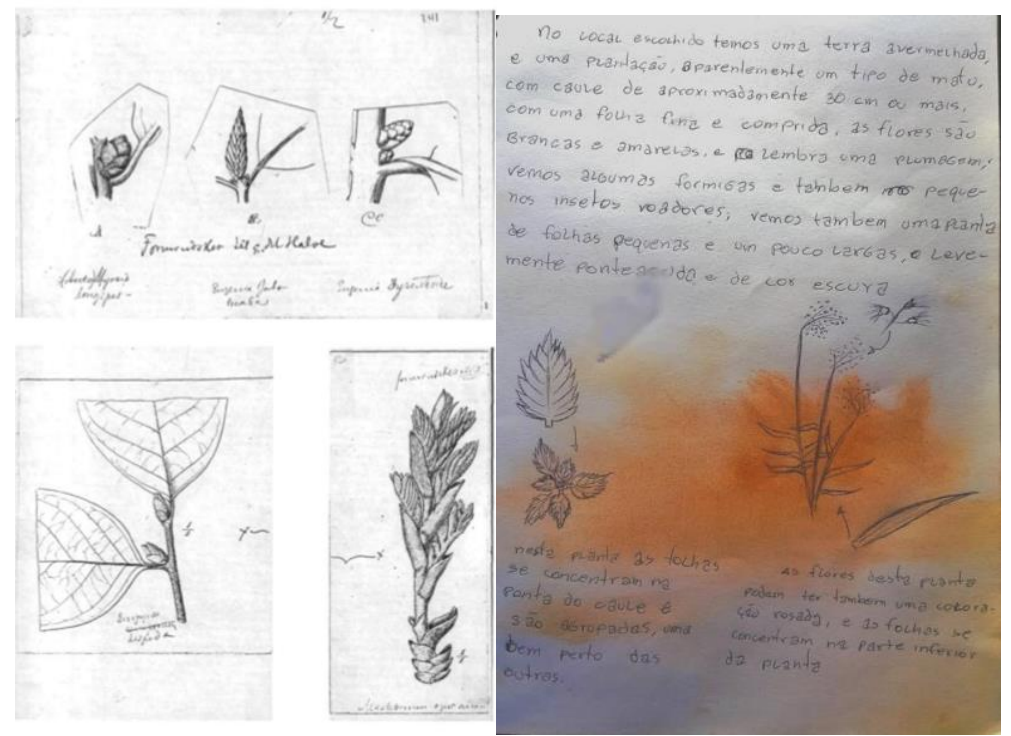

No local escolhido temos uma terra avermelhada e uma plantação, aparentemente um tipo de mato, com caule de aproximadamente 30 $\mathrm{cm}$ ou mais, com uma folha fina $e$ comprida. As fores são brancas e amarelas e lembram uma plumagem. Vemos algumas formigas e também pequenos insetos viadores. Vemos também uma planta de folhas pequenas e um pouco largas, e levemente pontiaguda e de cor escura.

Nesta planta as folhas se concentram na ponta do caule e são agrupadas, uma bem perto das outras.

As flores desta planta podem ter também uma coloração rosada, e as folhas de concentram na parte inferior da planta.

Figura 2: Esquema morfológico elaborado por Eugenius Warming (a esquerda) e descrição morfológica realizada por um aluno (a direita)

Fonte: KLEIN, Aldo Luiz, 2002; acervo pessoal dos autores e transcrição, respectivamente. 

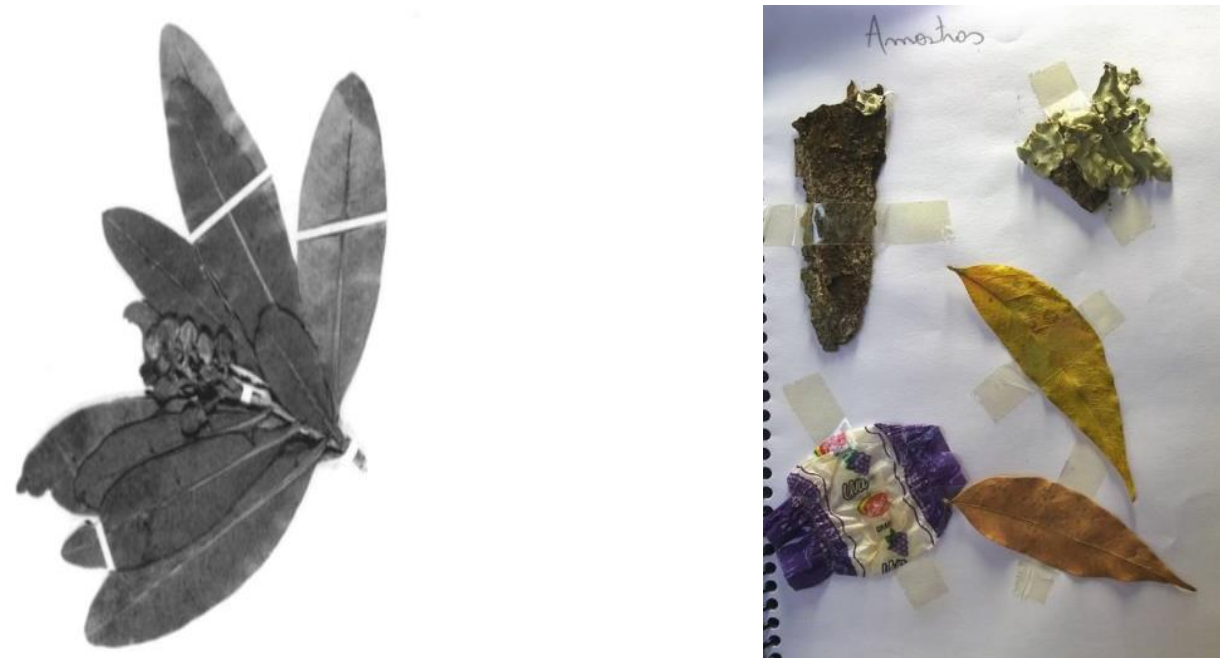

Figura 1: Coleta realizada por Eugenius Warming (a esquerda) e coleta realizada por um aluno (a direita) Fonte: KLEIN, Aldo Luiz, 2002; e acervo pessoal dos autores, respectivamente.

Entendemos que usualmente os métodos de aprendizagem ativos são entendidos segundo a ideia de que os estudantes aprendem melhor por experiência direta. Desde o início desta proposta até sua aplicação, cuidamos para não reproduzir esta ideia que, apesar de ser verdadeira em algumas situações, não deixa de ser reducionista e grosseira se o foco for apenas o "estar ativo". Nessa proposta, o essencial não foi manipular o objeto e o artefato concreto, mas sim o compromisso em buscar soluções e respostas para as questões colocadas.

\section{Considerações finais}

A partir da revisão bibliográfica realizada, percebemos a importância que o conhecimento histórico acerca da Ecologia e, inevitavelmente da Biologia, apresenta no processo de formação docente. Entender as bases históricas da Ciência em questão é de crucial importância para que o educador esteja consciente de sua prática docente, não se tornando refém dos manuais de educação, evitando a ocorrência de erros conceituais, históricos epistemológicos e filosóficos, além de se sentir mais seguro e capaz naquilo que faz. Do ponto de vista da atividade pedagógica proposta, entendemos que esta pode ajudar o professor a discutir com os alunos sobre a construção da ciência e as dificuldades enfrentadas pelos cientistas, confrontadas com as tecnologias disponíveis atualmente; além de, diversificar a prática docente. Finalmente sobre a formação de professores, consideramos que é importante incluir as discussões relacionadas à história e filosofia das ciências, em especial da biologia para que o professor em formação tenha subsídios para pensar em alternativas ao ensino de ciências presente hoje nas escolas. Esse é um dos objetivos do PIBID-Biologia da universidade aqui pesquisada. 


\section{Referências}

ALARCÃO, I. Escola reflexiva: nova racionalidade. Porto Alegre: Artmed Editora, 2001.

ANDRADE, K. dos S; BASTIANI, C. Viajantes naturalistas do século XIX na região da Província de Goiás: levantamento de topônimos indígenas. Antares, v.4, n. 8, p. 196-184, jul./dez. 2012.

BRANDO, F. da R.; ANDRADE, M. A. B. S.; MEGLHIORATTI, F. A.; CALDEIRA,

A. M. A. Contribuições da epistemologia e da história da ecologia para a formação de professores e pesquisadores. Filosofia e História da Biologia, v. 7, n. 2, p. 181-200, 2012.

BRAGA, P. D. Leopoldina de Habsburgo, rainha de Portugal. Escola Superior de Educação de Almeida Garrett, Lisboa, v. IV, p. 233-245, 2006.

CAMPOS, M. C. da C.; NIGRO, R. G. Teoria e prática em ciências na escola: o ensinoaprendizagem como investigação. São Paulo: FTD, 2009.

FLORI, M. Warming descobre o Brasil. Folha do Meio Ambiente. Editora Ltda, acervo digital, 2013. Disponível em <http://www.folhadomeio.com.br/publix/fma/folha/2013/07/2johannes242.html>. Acesso em 08 jul. 2014.

GIL PÉREZ, D.; MONTORO, I. F; ALÍS, J. C; PRAIA, J; Para uma imagem não deformada do trabalho científico. Ciência \& Educação, v. 7, n. 2, p. 125-153, 2001.

KLEIN, Aldo Luiz (Org.). Eugen Warming e o cerrado brasileiro. São Paulo: UNESP, 2002.

LAGOA SANTA. Prefeitura de Lagoa Santa - MG. Homenagem ao Pai da paleontologia brasileira. Disponível em < http://www.lagoasanta.com.br/homem/peter.htm>. Acesso em: 08 jun. 2015.

LISBOA, K. M. Viagem pelo Brasil de Spix e Martius: quadros da natureza e esboços de uma civilização. Ver. Bras. De Hist. São Paulo, v. 15, n. 29. p. 73-91, 1995.

MATTHEWS, M. R. História, filosofia e ensino de ciências: a tendência atual de reaproximação. Caderno Catarinense de Ensino de Física, Florianópolis, v. 12, n. 3, p.

164-214, 1995.

MELZER, M. e AIRES, J. A. A História do desenvolvimento da teoria atômica: um percurso de Dalton a Bohr. Amazônia, Revista de Educação em Ciências e Matemática, v.11 (22) Jan-Jun 2015. p.62-77.

MOREIRA, M. A., ZYLBERSZTA J. N, A., DELIZOICOV, D. \& ANGOTTI, J. A. P.. O papel do laboratório no ensino de ciências. In: I Encontro Nacional De Pesquisa Em Educação Em Ciências, Porto Alegre - RS, 1997.

PAZ, de O. de S.; OLIVEIRA, A. A.; SILVA, C. T.; HIRAOKA, A.; PEGORETTI, R. F. Caderneta de campo: importante material didático para as aulas de campo de geografia. LaboGeo - UFPR, 2014. Disponível em <http://bit.ly/2DIVVgR>. Acessado em 24/01/2016.

POLINARSKI, C. A.; DALZOTTO, E.; NUNES, M. J. C. Da história natural da Ecologia como área de estudos para a Biologia. In: Il Simpósio Nacional de Ensino de Ciência e Tecnologia, 2010.

SOUZA, R. B. F. Contribuições de atividades experimentais investigativas na aprendizagem de conteúdos microbiológicos. Dissertação de Mestrado - Universidade Federal de Mato Grosso, MT, 2014. 